\title{
Studies on Shelf-Life Evaluation of Reduced Sugar Jelly Confection
}

\author{
S. Priya ${ }^{1 *}$ and N. Prakash ${ }^{2}$ \\ ${ }^{1}$ College of Food and Dairy Technology, Tamil Nadu Veterinary and Animal Sciences \\ University, Chennai-600052, Tamil Nadu, India \\ ${ }^{2}$ Food Technologist, K.P. Manish Global Ingredients Private limited, \\ Chennai-600 003, Tamil Nadu, India \\ *Corresponding author
}

\section{A B S T R A C T}

Keywords

Fructose oligo

saccharide,

Blueberry, Low

sugar confection,

Shelf life,

Acceptance.

Article Info

Accepted:

23 June 2017

Available Online:

10 July 2017
The aim of this project is to reduce the sugar level in the jelly confectionery without affecting the sensory attributes and to increase the storage property of the jelly. Fructose oligo saccharide (FOS) was used to replace the sugar. Three different concentration of FOS was used at 6, 12, and $18 \%$. Jelly was prepared with a reduced amount of sucrose, citric acid, sodium benzoate, tri sodium citrate and low- esterified pectin. Blueberry pulp was added to the jelly. Physico-chemical parameters and microbiological load, were analyzed after storage of $15^{\text {th }}$, and $30^{\text {th }}$ day. From the overall results it can be concluded that the storage period has effect on the prepared reduced sugar jelly, but their quality remains good and has maximum consumer acceptance.

\section{Introduction}

Customer attitudes and behaviours have moved towards health foods because they have more concerns on increasing environmental stresses such as pollution and toxic substances in the environment. Environmental pollutants and lifestyle factors induce oxidative stress leading to many long term health complications in human such as diabetes, cancer and cardiovascular disease. WHO recommends a reduction of sugar consumption to below $5 \%$ of total energy intake (vs up to $15 \%$ now). Half of the consumer's world-wide is trying to reduce his or her sugar intake. "Low or No sugar" was among the top 3 priority of customers when purchasing foods and drinks in 2013. Basic Raw material for all confectionery product is Sucrose who is the culprit responsible for the type 2 diabetes. Reducing the sugar level in confectionery products creates texture problems in the final products. So replacing the sugar level in the confectionery articles is a tricky one to perform. Fructose Oligo Saccharide (FOS) is one of the dietary fiber used for sugar replacement in food products.

In the Global food market, confectionary industry play essential role. Usually confections are low in nutrients and high in calorie. Low sugar confections are gaining 
popularity because of its low calorific value, its nutritional health benefits. Oligosaccharides are very well recognized as 'functional food ingredients' because of their positive effects on human health. Oligosaccharides are relatively new functional food ingredients that have great potential to improve the quality of many foods. The production and application of food grade oligosaccharides are increasing and their major uses are in beverages, infant milk powders, confectionery, bakery products, yoghurts and dairy desserts. The use of oligosaccharides in livestock industry is also increasing (Crittenden and Playne, 1996). FOS possesses several properties, which make their use as food ingredients particularly attractive. They are water-soluble and mildly sweet, typically $30 \%$ as sweet as sucrose. Their relatively low sweetness is useful in food production when a bulking agent with reduced sweetness is desirable to enhance other food flavours. The viscosity and thermal stability of FOS solution is higher than that of sucrose at same concentration. Compared with mono and disaccharides, the higher molecular weight of oligosaccharides provides increased viscosity, leading to improved body and mouth feel. They control the browning reaction due to Maillard reactions in heat - processed foods. Because of their low water activity, high moisture retaining capacity they control the microbial contamination (Crittenden and Playne, 1996). FOS is present in certain natural foods such asparagus, sugar beet, onion, Jerusalem artichoke Bananas, Tomatoes, Chicory, Barley, Wheat etc. As a prebiotic, it can be considered beneficial to your health as it is virtually undigested by the human digestive system so arrives in the colon unaltered, providing a food source for beneficial bacteria, it has low calorific value, increases the population of bifidobacteria in the colon (Roberfroid et al., 1998 and Gibson et al., 1995). The objective of our research was to analyze storage stability of the developed low sugar confection and evaluate the acceptance level among the consumers.

\section{Materials and Methods}

Blueberry (vaccinium corymbosum) pulp was purchased from local market at Chennai, Tamil Nadu. Other ingredients for jelly preparation were purchased from Sigma Aldrich. Fructose oligo saccharide (FOS) and blueberry flavour were procured from KP MANISH Global Ingredients Pvt Ltd, Chennai.

The procedure described by Prakash and Priya (2016) was followed for making reduced sugar jelly confection. FOS was replaced at $6,12,18 \%$ and blueberry pulp was added at 5 and $10 \%$. Each treatment was replicated five times and average analytical values were obtained. Finished product was wrapped manually and stored for 30 days at $32^{\circ} \mathrm{C}$ and analyzed for physico-chemical, sensory and microbial attributes and storage to assess its shelf-life

\section{Physical and chemical measurements}

\section{Titratable acidity}

Titratable acidity also known as TA of a solution is an approximation of the solution's total acidity which is measured by reacting the acids present with a base such as sodium hydroxide $(\mathrm{NaOH})$ to a chosen end point, close to neutrality, as indicated by an acid sensitive color indicator. Titratable acidity of prepared jelly was measured by following procedure.

10 grams jelly was diluted with $50 \mathrm{ml}$ of water. Adding water does not change the total acidity of the jelly. Then 5 drops of phenolphthalein were added. It is an indicator that is clear when it is in a solution that is 
acidic, but will change to a purplish color when that solution becomes neutral to basic. Then $0.1 \mathrm{~N} \mathrm{NaOH}$ was added until the solution starts to turn pinkish and stay pinkish then note the amount of $\mathrm{NaOH}$ used for the titration. Following formulae was used to determine the Titratable acidity of the jelly

Titratable acidity $=\frac{\text { (Millilitre of } \mathrm{NaOH} \text { used) } \mathrm{X} 0.75}{\text { Milliliter of jelly sample used }}$

\section{Soluble solids content $\left({ }^{\circ}\right.$ Brix $)$}

Soluble solids content is expressed as ${ }^{\circ} \mathrm{Bx}$. It is used to express the sugar content of an aqueous solution. One ${ }^{\circ} \mathrm{Bx}$ is equal to 1 gram of sucrose in 100 grams of solution. TSS of the jelly was measured by table top HENNA refractometer and result expressed in ${ }^{\circ} \mathrm{Bx}$. It is very important that sufficient time to be allowed for the temperature equilibration of the sample.

\section{Ash test}

Total ash content is a useful parameter of the nutritional value of the food products. Ash test was determined by weight loss of jelly at $800^{\circ} \mathrm{C}$ for 2 hours.

Ash $\%=\frac{\text { (Weight of final sample(g) X100 }}{\text { weight of final sample(g) }}$

\section{Moisture content}

Approximately $5 \mathrm{~g}$ of jelly was weighed and placed in an aluminum pan. The samples were dried in a conventional oven at $105{ }^{\circ} \mathrm{C}$ for at least $24 \mathrm{~h}$. To reduce moisture absorption during weighing, the dried samples were cooled in a desiccator containing Calcium chloride for at least $30 \mathrm{~min}$. Moisture content was calculated using the following equation.

Moisture $\%=\frac{(\text { Wet weight }(\mathrm{g})-\text { Dry weight }(\mathrm{g})) \times 100}{\text { Wet weight }(\mathrm{g})}$

\section{pH measurements}

The $\mathrm{pH}$ of the jelly was measured using a $\mathrm{pH}$ meter (Systronics). The $\mathrm{pH}$ meter was calibrated daily with two buffer solutions $\mathrm{pH}$ 4.0 and $\mathrm{pH}$ 7.0. All measurements were performed at ambient temperature.

\section{Microbial analysis}

The prepared samples were evaluated for microbiological quality at day 1, 15, and 30 . Ten-gram jelly was diluted and homogenized in $90-\mathrm{mL}$ peptone water using Stomacher @bags. From this dilution, six consecutive dilutions were prepared for each sample. Microbiological tests were performed for yeast and mold and total aerobic plate count. The total counts were determined using aerobic count plates with incubation at $35^{\circ} \mathrm{C}$ for $48 \mathrm{~h}$. The yeast and mold were counted on days 3 and 5 after storing at ambient temperature.

\section{Sensory evaluation}

A total of 18 untrained panellists participated in the consumer study. Sensory evaluation was conducted in the Food Science (R\&D) Laboratory at KP Manish Global ingredients Private ltd. Because Blue berry jelly is the one of the most popular flavor for jams and jellies (International Jelly and Preserve Association 2003), each panelist evaluated three samples of jelly with different concentration of pulp. One sample was the target of this study, which is no sugar-added blue berry jelly, Jelly samples were offered to panelists on odorless plastic plates coded by three-digit random numbers at room temperature. Samples were served to panelists monadically. Jellies were consumed along with the bread pieces (Abdullah and Cheng 2001; Gajar and Badrie 2001). The panellists evaluated jelly on a 9point hedonic scale to determine the degree of liking for jelly products $(9=$ like extremely, 5 
$=$ neither like nor dislike, $1=$ dislike extremely). The samples were rated for Colour, flavour, body and texture, appearance and overall acceptability Analysis of variance ANOVA was used to determine the statistical significant difference between the three samples of jelly.

\section{Statistical analysis}

Three treatments of sugar-free jelly were subjected for physical and chemical properties. The storage period was 30 days at $4^{\circ} \mathrm{C}$ for refrigerated samples. All the refrigerated samples were tested at days 1,15 and 30. Sensory analysis was performed on 1 day old jelly. The data obtained were analyzed statistically using analysis of variance (ANOVA) to find if the differences were significant or not were determined, as mean with critical difference at $5 \%$ level.

\section{Results and Discussion}

\section{Titratable acidity}

The per cent titrable acidity for three different concentration increased on $30^{\text {th }}$ day of storage interval. Hossen et al., (2009) stated that the increase in acidity of guava jelly was due to fermentation and hydrolysis of sugar. Increase in acid content of jelly makes it firmer due to toughening of fibrils.

\section{Brix}

TSS of reduced sugar jelly was measured by table top HENNA refractometer and result expressed in ${ }^{\circ} \mathrm{Bx}$. It is very important that sufficient time to be allowed for the temperature equilibration of the sample.

\section{Ash}

Ash content between treated and untreated samples did not differ significantly during the storage period it was around the range of 0.42-0.49

\section{Moisture content}

The replacement of sugar free jellies with blueberry pulp treated with $18 \%$ of Fructoligosaccharide had slightly lower moisture content than the other concentrations which might be partly attributed to the change form crystalline to the amorphous form of substances which permits the binding of water. Similar results were observed by Yousif and Alghamdi (1999) for date jelly stored at $25^{\circ} \mathrm{C}$. However, this small difference was statistically significant. These low values for the moisture content for regular jelly resulted from the high soluble solids content, because these treatments have high amounts of sugars.

\section{pH measurements}

The $\mathrm{pH}$ did not significantly differ among days or treatments or treatment-day interaction during the 30 days of refrigerated storage or of accelerated shelf life. The $\mathrm{pH}$ values of these treatments ranged from 3.35 to 3.64 .

\section{Microbial analysis}

The replacement of reduced sugar jelly treatments exhibited no detectable yeast and mold during 30 days of refrigerated or accelerated shelf life storage. Jellies depend on their high sugar concentration for microbiological stability but in humid weather conditions may promote the growth of mold on the surface of the container as reported by Pilgrim et al., (1991). Addition of antimicrobial agent can inhibit the growth of microbes Hodgson and Kerr (1991). The result showed that the bacterial growth was very low till $15^{\text {th }}$ day from preparation. 
Table.1 Effect of storage on sensory attributes of reduced sugar jelly confection

\begin{tabular}{|l|c|c|c|c|c|c|}
\hline \multicolumn{1}{|c|}{ Storage } & \multicolumn{3}{|c|}{$\mathbf{1 5}^{\text {th }}$ Day } & \multicolumn{3}{c|}{$\mathbf{3 0}^{\text {th }}$ Day } \\
\hline Treatment & $6 \%$ & $12 \%$ & $18 \%$ & $6 \%$ & $12 \%$ & $18 \%$ \\
\hline Colour & $7.41 \pm 0.21$ & $7.45 \pm 0.31$ & $7.52 \pm 0.41$ & $7.46 \pm 0.62$ & $7.49 \pm 0.61$ & $7.53 \pm 0.63$ \\
\hline Flavour & $8.52 \pm 0.63$ & $8.54 \pm 0.21$ & $8.51 \pm 0.66$ & $8.54 \pm 0.64$ & $8.55 \pm 0.71$ & $8.59 \pm 0.71$ \\
\hline Body and Texture & $7.82 \pm 0.51$ & $7.71 \pm 0.65$ & $7.73 \pm 0.63$ & $7.83 \pm 0.63$ & $7.75 \pm 0.91$ & $7.74 \pm 0.21$ \\
\hline Appearance & $7.88 \pm 0.29$ & $7.84 \pm 0.38$ & $7.85 \pm 0.45$ & $7.72 \pm 0.41$ & $7.78 \pm 0.51$ & $7.75 \pm 0.58$ \\
\hline Overall Acceptability & $7.89 \pm 0.37$ & $7.74 \pm 0.21$ & $7.61 \pm 0.02$ & $7.79 \pm 0.02$ & $7.69 \pm 0.01$ & $7.59 \pm 0.25$ \\
\hline
\end{tabular}

After that microbial growth takes exponential phase resulting more than 300 colonies. Low values of Standard Plate Count were recorded for pear jelly after 180 days (Sudhagar et al., 2005). No fungal growth was observed during the storage period of guava jelly which supports our results (Hossn et al., 2009). To maintain the microbial growth under the limit, increasing the concentration of the preservative is strongly recommended. From this result can indirectly predict that FOS is responsible for the exponential microbial growth in jelly. Hence it can act as a prebiotic as well when it is taken.

\section{Sensory Evaluation}

Sensory evaluation was carried out for the three different treatment at regular intervals. Mean values of colour, flavour, Appearance, Body and texture and overall acceptability are listed in table 1 . The result of the acceptance panels did not show any significant difference statistically among different treatments. Colour and Flavour increased on prolonged storage condition. The values were similar for whey based mango jelly and dragon fruit jelly Kumari and Sandal (2010) and Islam et al., (2012). No remarkable changes were recorded in flavour upto the storage of 210 days for guava jelly Hossen et al., (2009) and jelly prepared from Karonda fruits (Deen and Singh 2013). The scores for body and texture increased at the end of storage period. High acidity might be responsible for more firmness of jelly based confection. Similar results were recorded by Freedman and Francis (1984). The result suggest that low sugar jelly confection developed with blueberry extract was more acceptable by the consumers for all the sensory attributes that the jelly commercially available in the market.

From the overall results it can be concluded that the storage period has effect on the prepared reduced sugar jelly, but their quality remains good and has maximum consumer acceptance. Therefore, the developed reduced sugar jelly can be included in the daily diet of every age group which can increase the sensory attributes and helps to maintain a good health. FOS being used as a low calorie sweetener and also known for its interesting nutritional and functional properties which enhance the shelf life and organoleptic properties of various food products. FOSs are on the leading edge of the emerging trend towards functional foods.

\section{References}

Crittenden, R.G., and Playne, M.J. 1996. Production, properties and applications of food - grade oligosaccharides. Trends in Food Science and Technology, 7, 353-360.

Roberfroid, M.B., 1998. The Bifidogenic Nature of Chicory Inulin and its Hydrolysis Products; Journal of Nutrition. 128, 11-19

Gibson, G.R., 1995. Selective Stimulation of 
Bifidobacteria in the Human Colon by Oligofructose and Inulin; Gastroenterology, 108(4): 97582

Prakash, N., and Priya, S. 2016. Development of novel functional confectionery using low reduced sugar. Indian Journal of Drugs. 4(4): 141-148

Abdullah, A., and Cheng, T. C. 2001. Optimization of reduced calorie tropical mixed fruits jam. Food qual. Pref. 12(1), 63-68.

Gajar, A.M., and Badrie, N. 2001. Processing and quality evaluation of a low-calorie christophene jam (Sechium edule [Jacq.]) Swartz. J. Food Sci. 67(1), 341346.

Hossen, S., Kabir, M. S., Uddin, M.B., Rahman, A.K.M.L. and Mamun, M.R.A. 2009. Effect of different extractions of juice on quality and acceptability of guava jelly. $J$. Innovative Dev. Strategy, 3: 27-35.

Yousif, A.K., and Alghamdi, A.S. 1999. Suitability of some date cultivars for jelly making. J. Food Sci. Technol., 36:515-518.

Sudhagar, T., Manimegalai, G., and Saravanakumar, R. 2005. Effect of packaging materials on storage stability of pear jelly. Beverage and Food World,
32: 86-87.

Hodgson, A.S. and Kerr, L.H. 1991. Tropical Fruit Products. In The Chemistry and Technology of Pectin (R.H. Walter, Ed.) Pp. 67-86. Academic Press, Inc., San Diego, Ca.

International Jelly and Preserve Association. 2003. Jam and Jelly Lore. Http://Www.Jelly.Org/Lore.Html.

Pilgrim, G.W., Walter, R.H. And Oakenful, D.G. 1991. Jams, Jellies, and Preserves. In The Chemistry and Technology of Pectin (R.H. Walter, Ed.) Pp. 23-50, Academic Press, Inc., San Diego, Ca.

Kumari, A. and Sandal, A. (2010). Quality parameters of mango jam supplemented with whey and changes during storage. Indian Food Packer, 64: 126-144.

Islam, M.Z., Khan, M.T.H., Hoque, M.M. and Rahman, M.M. (2012). Studies on the processing and preservation of dragon fruit (Hylocereus undatus) jelly. The Agriculturists, 10: 29-35.

Deen, B. and Singh, I.S. 2013. Studies on preparation and storage of jelly from Karonda (Carissa carandas L.) fruits. Beverage and Food World, 40:60-64.

Freedman, L. and Francis, F.J. 1984. Effect of ascorbic acid on colour of jellies. $J$. Food Sci., 49:1212-1213.

\section{How to cite this article:}

Priya, S. and Prakash, N. 2017. Studies on Shelf-Life Evaluation of Reduced Sugar Jelly Confection. Int.J.Curr.Microbiol.App.Sci. 6(7): 2399-2404. doi: https://doi.org/10.20546/ijcmas.2017.607.283 